\title{
O ERRO NO PROCESSO DE ENSINO-APRENDIZAGEM DA MATEMÁTICA: ERRAR É PRECISO? ${ }^{1}$
}

\author{
Alina Galvão Spinillo \\ Professora, UFPE \\ alinaspinillo@hotmail.com \\ Auxiliadora Baraldi Pacheco \\ Professora, Instituto Federal de Alagoas \\ barauxi@gmail.com \\ Juliana Ferreira Gomes \\ Professora, UFPE \\ juferreira320@hotmail.com \\ Luciano Cavalcanti \\ Professor, UFPE/Campus de Garanhuns \\ lucianocavalcanti@yahoo.com.br
}

\section{Resumo}

$\mathrm{O}$ artigo discute diferentes concepções e maneiras de lidar com o erro no processo de ensino-aprendizagem da matemática. Partindo da ideia de que errar é inevitável na prática escolar, o artigo trata da questão de como transformar o erro em algo didaticamente produtivo. Ressalta-se o papel do erro na expressão e na aquisição de conhecimentos matemáticos, bem como a importância de inseri-lo no planejamento e na dinâmica da sala. As concepções e propostas discutidas são ilustradas com exemplos retirados de pesquisas conduzidas em sala de aula e em situações controladas de investigação, versando sobre resoluções de problemas matemáticos por crianças.

Palavras-chave: Concepções sobre o erro, Análise de erros, Ensino-aprendizagem, Educação Matemática.

\section{THE ERRORS IN THE PROCESS OF TEACHING AND LEARNING OF MATHEMATICS: ARE THEY NECESSARY?}

\begin{abstract}
The present article discusses different ideas and ways of dealing with errors in the process of teaching and learning of mathematics. Taking as a starting point the idea that to make mistakes is inevitable during the schooling setting, the article addresses the question of how to turn the making of errors into something didactically productive. The article highlights the role of mistakes in the expression and acquisition of mathematical knowledge, as well as the importance of including them in the planning of lessons and in the classroom dynamics. The ideas and proposals discussed are illustrated with examples taken from research conducted in the classroom and in controlled investigative situations, focusing on the solution of mathematical problems by children.
\end{abstract}

\footnotetext{
${ }^{1}$ Boletim Gepem (Online) ISSN: 2176-2988 | n. 64 - Jan./Jun. 2014 (texto em diagramação).
} 
Key words: Conceptions about errors, Error analysis, Teaching and learning, Mathematical education.

Um dos grandes desafios para alunos e professores refere-se à maneira de tratar o erro no processo de ensino-aprendizagem da matemática. Se, por um lado, não há consenso quanto à forma de lidar com o erro, por outro lado, há consenso quanto à constatação de que errar é inevitável na prática escolar. A questão que se coloca, portanto, é como transformar o erro em algo didaticamente produtivo. A este respeito, é relevante discutir as diferentes concepções sobre o erro e as implicações que essas concepções têm para a prática pedagógica do professor de matemática. Essas concepções têm origens teórico-filosóficas distintas, gerando implicações educacionais também diferentes.

\title{
O erro como algo a ser corrigido
}

\begin{abstract}
“O propósito de se ensinar Matemática é apontar erros e corrigi-los. Este parece ser o entendimento comum sobre o que é Educação Matemática para muitos alunos. Chegamos a presenciar crianças na pré-escola manifestarem esse mesmo ponto de vista em pecinhas teatrais sobre o ensino de matemática. Uma criança desempenhava o papel de professor, e as demais eram "alunos". Um "aluno" que deveria resolver um exercício no quadro escreveu uma fileira cheia de símbolos aparentemente sérios. Em seguida, o "professor" apagou alguns símbolos e escreveu outros no lugar, apontando os erros do "aluno". Assim, antes mesmo de ter experimentado aulas de matemática por si próprio, as crianças já demonstram uma compreensão de que errar e corrigir são parte integrante da Educação Matemática." (ALRO; SKOVSMOSE, 2006, p. 21)
\end{abstract}

Os autores iniciam seu livro com a passagem acima, comentando que algumas práticas pedagógicas apoiam-se na ideia de que os erros podem ser eliminados com o simples ato de apagar o que foi feito no quadro, no caderno ou no livro de exercícios. $\mathrm{O}$ que parece estar subjacente a este ato é a crença de que a forma equivocada de raciocinar poderia também ser apagada e substituída por outra. Segundo os autores, há um absolutismo pedagógico que fundamenta as ações didáticas, tornando a correção a principal alternativa, se não a única, que é adotada para lidar com os erros dos alunos.

Pacheco e Medeiros (2009) comentam que é comum no ensino da matemática interpretar o erro como um fracasso que pode ser revertido a partir da mera correção que 
geralmente consiste em apontar o erro e indicar o que deve se feito. De fato, a ação pedagógica mais utilizada é a substituição de um procedimento considerado inadequado por um considerado apropriado. Mas de que forma o aluno errou? Por que ele errou? O que expressa este tipo de erro? Que orientação dar ao aluno sobre este tipo de erro? Essas são questões que não são respondidas quando se adota a perspectiva de que o erro deve ser corrigido.

Outra característica desta perspectiva é privilegiar o produto final, desconsiderando o processo de resolução, tendendo-se a aceitar como correto apenas os procedimentos de resolução usuais em detrimento de outras formas de proceder. A esse conjunto de ações didáticas Alro e Skovsmose (2006) denominam de absolutismo burocrático que estabelece o que é certo e o que é errado, regendo, assim, as formas de comunicação na sala de aula. Tal perspectiva gera a ideia de que a principal função do professor é corrigir erros.

Não se deseja, contudo, fazer-se uma apologia ao erro, pois, como afirma Spinillo (1995) e Santos e Buriasco (2008), muitas vezes tem-se a visão equivocada de que os erros não podem ser corrigidos. Pinto (2000) comenta que a não correção das atividades na sala de aula é um mecanismo sutil de legitimação do fracasso escolar que afasta o professor do cenário pedagógico. Na realidade, a visão espontaneísta que preconiza uma aceitação incondicional dos erros é tão indesejável quanto o absolutismo pedagógico que gera uma aversão ao erro.

Para muitos, os erros devem ser eliminados, pois são comportamentos que sinalizam o fracasso e indicam a ausência de conhecimento matemático. Nesta abordagem, o erro se circunscreve à avaliação que, na maioria das vezes, pouco retorno traz para a aprendizagem. Tal noção se apoia na concepção de aprendizagem como formação de hábitos através de conexões entre estímulos e respostas, centrada em uma série de reforços positivos frente ao acerto e reforços negativos frente aos erros de modo a diminuir seu aparecimento. Nesta perspectiva, o erro não tem lugar na aquisição de conhecimentos matemáticos, perspectiva distinta daquelas discutidas adiante.

\section{O erro como forma de conhecer o raciocínio dos alunos}


que é pertinente perguntar se os erros são fatos aleatórios da aprendizagem ou se têm suas razões no mecanismo de aquisição dos conhecimentos." (CASÁVOLA et al., 1988, p. 32)

Com raízes na Psicologia Cognitiva, esta concepção postula que o erro está associado a mecanismos de aquisição de conhecimentos que especificam e revelam uma lógica na organização intelectual dos indivíduos.

Assim, seria de interesse de todo professor compreender os erros que surgem na sala de aula de matemática, particularmente aqueles identificados como sistemáticos e estáveis que estão relacionados ao fato dos alunos se equivocarem da mesma maneira quando diante de certas situações-problema. Os erros, assim como os acertos, são formas de raciocinar que revelam os limites e as possibilidades do pensamento frente a um dado objeto de conhecimento, no caso, os conceitos matemáticos. Esta é uma abordagem construtivista (BOTELHO et al, 2006; CASTRO et al, 2006; SPINILLO, 1999) em que o erro não é algo que falta, mas algo que o aluno apresenta em uma dada situação e em um dado momento (SANTOS \& BURIASCO, 2008), precisando ser interpretado uma vez que é o resultado de conhecimentos matemáticos (RADATZ, 1979).

Mas como compreender as formas de raciocinar dos alunos para então interpretar os erros e identificar sua natureza? Um exemplo que ilustra esta possibilidade é a pesquisa de Spinillo e Silva (2010) em que foram identificadas diferentes estratégias incorretas empregadas por crianças de oito anos na resolução de problemas de produto cartesiano, como tratado a seguir.

\section{Exemplo 1}

Pedro tem três calças (preta, marrom e azul) e cinco camisas (amarela, vermelha, verde, laranja e cinza). Ele pode combinar as calças com as camisas para formar conjuntos. Quantos conjuntos diferentes Pedro pode formar?

Resolução

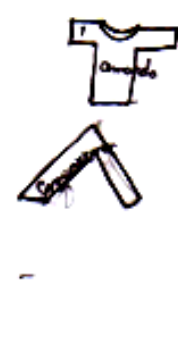

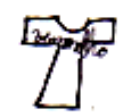
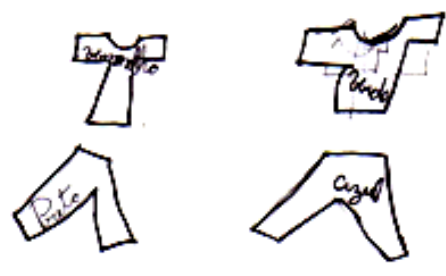

A explicação da criança foi que "Pedro só tem três calças, as camisas laranja e cinza vão sobrar; se ele tivesse cinco calças dava pra fazer cinco conjuntos, mas ele só tem três". O equívoco consiste no fato de raciocinar em termos de pares fixos que não 
podem ser desfeitos, não aceitando a possibilidade de uma calça vir a ser combinada com mais de uma camisa.

Exemplo 2

Um parque de diversão tem seis entradas $(\mathrm{A}, \mathrm{B}, \mathrm{C}$, D, E, F) e duas saídas $(1,2)$. Combinando as entradas e saídas Daniela pode fazer caminhos para entrar e sair do parque. De quantas maneiras diferentes ela pode entrar e sair desse parque?

Observa-se que a criança adota o esquema de correspondência um-para-muitos, aceitando que uma entrada pode ser combinada com mais de uma saída, como evidencia sua explicação: "Entra na A e sai na 2, entra na B e sai na 1, entra na $\mathrm{C}$ e sai na 1, entra na $D$ e sai na 2, entra na $E$ e sai na 1 , entra na $F$ e sai na 2\%. Entretanto, falta sistematização na constituição dos pares, o que faz com que nem todos os pares sejam formados. Esta estratégia indica o início do raciocínio combinatório, uma vez que a correspondência um-para-muitos, que é um dos princípios invariantes do produto cartesiano, é empregada na resolução do problema.

Esses erros revelam diferenças marcantes quanto à forma de raciocinar. Enquanto no Exemplo 1 a criança forma pares fixos, no Exemplo 2, a formação de pares é flexível, expressando uma noção inicial acerca do princípio da correspondência umpara-muitos. Embora os dois exemplos sejam resolvidos de forma inapropriada, as respostas erradas podem expressar níveis distintos de compreensão.

Pacheco e Medeiros (2009) documentam que mesmo entre estudantes do ensino médio identificam-se erros de diferentes tipos quanto ao raciocínio combinatório, sendo que alguns deles decorrem do fato do enunciado do problema gerar confusão entre a noção de arranjo e a de combinação. Este fato se refere à proximidade conceitual entre os conteúdos ensinados que pode propiciar a ocorrência de determinados erros, como se nota na resolução de problemas em que a área é confundida com o perímetro (ver exemplo adiante).

Em pesquisa sobre adição de frações, Cruz e Spinillo (2004, p. 15) identificaram erros distintos entre alunos do ensino fundamental na resolução da seguinte operação: 1/4 $+1 / 4$. 
Exemplo 3

Criança: Vinte e oito (escreve 28)

Examinadora: Como você fez?

Criança: Eu juntei os de cima (numeradores somados entre si, resultando 2) e os de baixo denominadores somados entre si, resultando 8)

Exemplo 4

Criança: escreve o traço da fração, soma os numeradores, colocando o resultado acima do traço da fração e em seguida soma os denominadores, colocando o resultado abaixo do traço de fração: $2 / 8$

Examinadora: Como você fez?

Criança: Eu somei esse (numerador 1 na primeira parcela) com esse (numerador 1 na segunda parcela) e esse (denominador 4 na primeira parcela com esse (denominador 4 na segunda parcela).

No Exemplo 4 o aluno demonstra algum conhecimento acerca do simbolismo matemático próprio de frações, somando separadamente os numeradores e os denominadores, obtendo como resultado um número fracionário. No Exemplo 3, entretanto, não se observa este tipo de conhecimento, pois o aluno percebe as frações como números inteiros.

Mais evidências de que as razões que levam os alunos a cometer erros são distintas foram documentadas por Gitirana, Magina, Campos e Spinillo (2014) com alunos do $1^{\circ}$ e do $2^{\circ}$ ciclo do ensino fundamental ao resolverem problemas das estruturas multiplicativas.

Exemplo 5

A sala de aula da escola Escola Divertida tem um formato retangular com 3 metros de largura e 5 de extensão. Qual é a área da sala de aula?

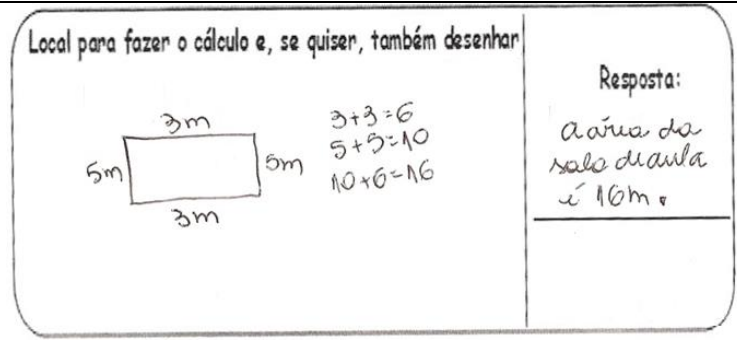


Confundindo a noção de área com a de perímetro, a criança adiciona os quatro lados, obtendo "16 m" como resultado. Por sua vez, outra criança resolve este mesmo problema da seguinte maneira:

Exemplo 6

A sala de aula da escola Escola Divertida tem um formato retangular com 3 metros de largura e 5 de extensão. Qual é a área da sala de aula?

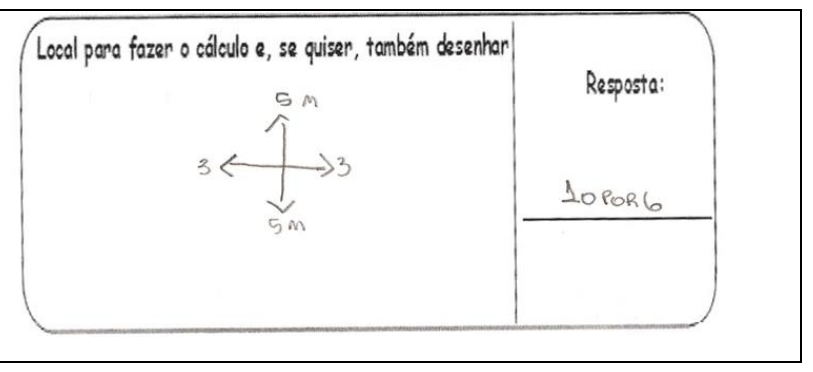

Embora se possa pensar que os erros sejam idênticos, uma análise mais detalhada mostra que o erro no Exemplo 6 está associado a uma forma de raciocinar mais sofisticada do que no Exemplo 5, pois o uso das setas relacionando os dois lados da sala que medem cinco metros e os dois lados que medem três metros sugere uma compreensão inicial acerca de que área é uma medida aplicada ao espaço ocupado no interior do retângulo, e não à soma do comprimento dos lados. Importante comentar que ao escrever a resposta, o aluno adota uma linguagem apropriada para referir-se à área: "10 por 6".

Interpretar os erros torna possível compreender que estes podem decorrer de formas de raciocinar distintas, umas mais e outras menos elementares. Além disso, há casos em que os erros decorrem da interferência de conhecimentos matemáticos prévios, como se observa no Exemplo 7, documentado por Cruz e Spinillo (2004), em que o conhecimento sobre os números inteiros leva a erros na resolução de adição de frações.

\section{Exemplo 7}

Operação apresentada: $1 / 4+1 / 4+1 / 4+1 / 4$

Criança: Vinte (escreve 20 no papel).

Examinadora: Como você fez?

Criança: Porque $4+1$ dá 5 . E $5+5$ dá 10 . Mais 5 , dá 15 . E mais 5 , dá 20. (soma o numerador e o denominador da primeira parcela, chega a um resultado, procedendo desta mesma forma em relação às demais parcelas, contando, então, de 5 em 5). 
Diferenças entre os tipos de erros também dizem respeito ao fato de que muitas vezes eles refletem maneiras distintas de lidar com uma dada situação. Segundo Santos e Buriasco (2008), ao compreender os sentidos e significados atribuídos ao problema e aos procedimentos de resolução adotados, é possível negociar com os alunos outras maneiras de interpretar e de resolver os problemas, convidando-os a legitimar diferentes tipos de conhecimento sem adotar uma visão dicotômica de certo e errado.

Essas considerações podem nortear as ações a serem adotadas frente as dificuldades dos alunos. Sobre isso, Cury (2012) ressalta a importância do conhecimento por parte dos professores acerca dos erros dos alunos e de formas de analisá-los. Peng e Luo (2009) comentam que ainda há muito a examinar sobre o modo como os professores de matemática lidam com os erros, enfatizando que a análise de erros faz parte da rotina do ensino e precisa compor o conjunto de conhecimentos que habilitam o indivíduo para a docência.

\section{O erro como ferramenta didática}

\footnotetext{
“... não há por que ter medo ou evitar o erro. A questão é como transformá-lo em um problema, em um diálogo, em uma situação de aprendizagem.” (MACEDO, 1990, p. 83.)
}

As expressões "aproveitamento didático do erro" (empregada por Lopes, ao prefaciar o livro de CURY, 2008), "trampolim para a aprendizagem" (adotada por BORASI, 1996) e "estratégia didática" (amplamente mencionada por PINTO, 2000) referem-se à possibilidade de transformar o erro em algo produtivo para a aprendizagem, sendo esta linha de pensamento compartilhada por autores tanto em discussões teóricas como a partir de dados empíricos acerca do erro em matemática (ASTOLFI, 1999; TORRE, 2007; GÓMEZ, 1995; MOREN, DAVID, MACHADO, 1992). Para estar a serviço da aprendizagem, o erro precisa assumir um status privilegiado tanto no planejamento das aulas como na dinâmica da sala.

\section{O erro inserido no planejamento e na dinâmica das aulas de matemática}

Os erros são previsíveis e podem ser incorporados à prática docente, fazendo parte do planejamento e da dinâmica das aulas. É comum saber-se qual a dificuldade 
que os alunos de determinado ano enfrentam em relação a um dado conteúdo de matemática. Em sendo assim, é possível prever quais os tipos de erros que terão ao serem introduzidos àquele conteúdo e transformá-los em estratégia didática, criando situações que provoquem a emergência desses erros para torná-los observáveis.

Borasi (1996) sugere que a dinâmica da sala de aula poderia voltar-se para a criação de um ambiente em que um determinado erro seria usado para questionar os alunos a respeito de outras formas de resolução mais apropriadas. O professor poderia ter um repertório de erros interessantes que pudessem ser trazidos para discussão ou criar situações geradoras de erros. Em outras palavras, é importante criar oportunidades para que os erros emerjam, sobretudo aqueles relacionados a conhecimentos prévios que se tornam obstáculos na aprendizagem de novos conceitos matemáticos.

A este respeito, Brousseau (1997) afirma que há erros que se derivam de um conhecimento prévio que impedem ou interferem na aquisição de um novo conhecimento matemático, como ocorreu no Exemplo 6 citado anteriormente em que o conceito de perímetro gerou erros em problemas sobre área, e no Exemplo 4 em que o conhecimento sobre os números inteiros gerou erros na adição de frações. Gitirana (2012, p. 64) ilustra este tipo de interferência ao mencionar como os alunos operam com números negativos, respondendo que "não pode" ou "um" como resultado da operação 2-3. Para a autora, essas respostas se derivam de regras anteriormente apresentadas de que "não se pode tirar o maior do menor". Desta forma, a origem desses erros está em conhecimentos advindos de conhecimentos prévios e de situações didáticas que os induzem, sendo denominados de obstáculos didáticos.

A ideia de tornar o erro um observável norteou a pesquisa conduzida por Lautert, Spinillo e Correa (2012) acerca do conceito de divisão. De acordo com a literatura uma das principais dificuldades que as crianças têm com este conceito referem-se à compreensão das relações inversas entre o divisor e o dividendo. Com o objetivo de auxiliar na superação desta dificuldade, as autoras realizaram um estudo de intervenção em que uma das atividades requeria que as crianças deliberadamente identificassem e refletissem acerca de formas equivocadas de resolução de problemas de divisão que lhes eram apresentadas. Era dito que aquelas formas de resolução inadequadas haviam sido feitas por alunos de outra escola ao resolverem um dado problema de divisão que era também apresentado. Esta atividade dava visibilidade ao erro que era colocado em evidência, passando a ser objeto de reflexão e análise. Uma atividade como esta pode ser facilmente desenvolvida em sala de aula e passar a fazer 
parte do plano de aula do professor que pode incluir atividades que promovam uma reflexão sobre os erros comumente experimentados pelos alunos frente a um determinado conceito matemático.

A perspectiva ora defendida opõe-se àquela que considera que o erro deve ser corrigido e eliminado da sala de aula. Aquela perspectiva se apoia na necessidade de afastar o erro do cenário pedagógico, como ocorre, por exemplo, quando um aluno é convidado a resolver um determinado problema no quadro. Em uma situação como esta, geralmente o aluno escolhido é aquele que sabe resolver corretamente o problema. Em uma sala em que o professor adota a perspectiva de dar visibilidade ao erro, o aluno chamado ao quadro seria aquele que teria se equivocado e seus procedimentos de resolução seriam objeto de reflexão e análise por toda a sala com vistas a comparar com outras formas de resolução e a encontrar procedimentos mais apropriados.

A ideia de que o erro tem papel construtivo no processo de ensino-aprendizagem encontra respaldo na teoria de Piaget que aponta a importância da tomada de consciência como suporte para as mudanças nos modos de pensar dos indivíduos.

\section{O erro como objeto de reflexão e análise: o papel da metacognição}

Conceber o erro como uma forma de raciocinar permite que seja feita uma teorização sobre ele, assim como se derivam repercussões sobre a dinâmica da sala de aula de modo a se criar situações em que o erro passe a ser efetivamente considerado no processo de ensino-aprendizagem. Duas situações podem ser promovidas em sala de aula para que o erro cumpra seu papel neste processo: a explicitação verbal das formas de pensar adotadas pelos alunos e o retorno cognitivo oferecido pelo professor acerca dessas formas de pensar.

No que concerne à explicitação verbal, perguntas como "Como pensou para resolver este problema?" ou "Me explica como descobriu que era este o resultado?" levam o aluno a explicitar seus modos de pensar e de proceder frente a uma situaçãoproblema. Este tipo de procedimento é amplamente adotado na aplicação do método clínico piagetiano em pesquisas no campo da Psicologia Cognitiva. Da mesma forma que para Piaget a resposta dada a tais perguntas permitia que o examinador tivesse acesso às formas de pensar da criança, para o professor tais perguntas permitem que ele igualmente saiba como seu aluno raciocina. No entanto, o que se deseja ressaltar aqui é que além deste ganho, tais perguntas levam o próprio aluno a tomar consciência de suas formas de pensar e de proceder. Esta tomada de consciência é fundamental para a 
compreensão, e consequentemente, para a aprendizagem (ver JOU \& SPERB, 2006; RIBEIRO, 2003; SPINILLO, 1999).

Spinillo (2003) relata uma experiência de ensino realizada em uma sala de $2^{a}$ série (atual $3^{\circ}$ ano) do ensino fundamental a respeito do conceito de proporção em que a professora solicitava que os alunos explicitassem suas formas de raciocinar e confrontassem suas ideias com as dos colegas, comparando-as e avaliando-as. A dinâmica instaurada permitia que a professora compreendesse e acompanhasse o modo de pensar dos alunos e, ainda, que cada aluno tomasse consciência de sua própria maneira de raciocinar. Sistematicamente os alunos respondiam perguntas como: "Como fez?", "Por que fez assim?", “Como pensou para resolver?”, independentemente de haver acertado ou não a resolução dos problemas. Ao responder essas perguntas o aluno realizava uma atividade metacognitiva.

A metacognição é a capacidade do indivíduo de avaliar, monitorar e autorregular os processos cognitivos; ou seja, de pensar sobre os próprios pensamentos que permite tomar consciência sobre o que se está fazendo ou pensando em uma dada situação (FLAVELL, 1987). Ela pode ativar os processos de raciocínio que são fundamentais para a resolução de problemas. Uma das grandes mudanças no desenvolvimento cognitivo nos anos escolares é a aprendizagem de como potencializar o uso das capacidades cognitivas mediante as capacidades metacognitivas. $\mathrm{O}$ pensar sobre o erro surge, portanto, como uma oportunidade não só de aprender o conteúdo matemático sobre o qual o erro incide, mas de se desenvolver cognitivamente de maneira mais ampla.

Na dinâmica da sala de aula é necessário, ainda, oferecer um retorno cognitivo aos alunos acerca de suas formas de raciocinar. Esta ação vai muito além de uma mera correção ou feedback. Para Spinillo (1995), o retorno cognitivo diz respeito a uma ação didática que envolve discutir com o aluno seus erros, esclarecendo as possíveis fontes de dificuldades, a natureza do erro e as formas de superá-lo. $\mathrm{O}$ retorno visa a compreensão e não a mera informação sobre o desempenho apresentado. Assim, para que haja uma compreensão plena do erro, é necessário que o próprio aluno analise seu modo de pensar e proceder.

\section{Considerações finais}

A resposta à pergunta inicial contida no título deste artigo é "Sim". Diante das discussões aqui tecidas a respeito do erro na educação matemática, a resposta é que 
"Errar é preciso". Não só é preciso, como também inevitável. Se não houvesse erros, não haveria aprendizagem, pois tudo estaria, de antemão, aprendido e conhecido. Portanto, a ideia ainda remanescente de que os erros precisam ser evitados e eliminados da prática escolar não se sustenta, não apenas por razões teóricas, mas, também, por razões empíricas: não há situações de aprendizagem sem equívocos, sejam eles advindos de dificuldades de compreensão de natureza epistemológica, psicológica ou didática.

Assim, é relevante saber o que os erros informam sobre o modo de raciocinar dos alunos e saber o que fazer (e como fazer) com eles nas aulas de matemática. Na realidade, é possível dizer que ao assumir a perspectiva de que o erro pode ser entendido como uma ferramenta didática assume-se também a perspectiva de que é necessário conhecer o raciocínio do aluno. Em última instância, o ponto principal é o significado que é atribuído ao erro por quem ensina. A partir da concepção adotada decorre o que fazer com o erro na sala de aula: ignorá-lo, corrigi-lo simplesmente ou transformá-lo em uma ferramenta didática.

Explorar essas questões requer transitar entre a Psicologia e a Educação. Compreender a natureza do erro e procurar padrões no modo de errar têm repercussões importantes sobre propostas educacionais que favoreçam a superação das dificuldades, reorganizando o pensamento dos alunos sobre determinado conceito ou conteúdo matemático.

Contudo, além de revelar ao professor como seus alunos pensam, a análise do erro cumpre ainda o papel de permitir que este seja didaticamente aproveitado no sentido mais nobre que a palavra aproveitamento possa assumir. Neste sentido, o erro além de inevitável, passa a ser observável, ou seja, didaticamente visível para alunos e professor. Tal postura requer que o erro seja interpretado. A análise de erros, dentre outros aspectos, leva à constatação de que nem todo erro é igual e de que muitos erros podem ser expressão de um mesmo padrão ou modo de raciocinar, sendo crucial promover ações didáticas específicas que incidam sobre erros de um mesmo tipo e que variem de um tipo de erro a outro. Portanto, identificar e corrigir erros não são ações suficientes para gerar mudanças nas formas de pensar, sendo necessário criar oportunidades em que o aluno possa refletir e analisar os erros que apresentou frente a uma dada situação.

Teorizando acerca desta dinâmica na sala de aula, ressalta-se o papel da metacognição na aprendizagem como uma atividade cognitiva de segunda ordem 
(pensar sobre o pensar) capaz de levar o aluno a tomar seu modo de proceder e de racionar como objeto de reflexão e análise. A emergência do erro surge como uma oportunidade para realizar uma atividade metacognitiva em que a explicitação verbal permite que o aluno dê visibilidade às suas formas de pensar.

Para concluir, os erros precisam ser sistematicamente explorados (PINTO, 2000), tendo papel construtivo na aquisição do conhecimento matemático (CASÁVOLA et al, 1988). Deste modo, parece ser importante incluir no leque de competências para o ensino, conhecimentos acerca de como lidar com os erros dos alunos. Na realidade, lidar com os erros em sala de aula é mais do que saber que o aluno está errado e saber ensinar a resposta correta, é preciso saber mais sobre análise de erros e tomar consciência de seu potencial didático no ensino de matemática. Em outras palavras, é necessário desenvolver no professor de matemática um conhecimento pedagógico dos erros, como propõe Cury (2012).

\section{Referências}

ALRO, H.; SKOVSMOSE, O. Diálogo e aprendizagem em Educação Matemática. Belo Horizonte: Autêntica, 2006.

ASTOLFI, J. P. El “error”: um medio para enseñar. Sevilha: Díada, 1999.

BORASI, R. Reconceiving mathematics instruction: a focus on errors. Norwood, NJ: Ablex Publishing Corporation, 1996.

BOTELHO, D. et al. Análise do erro na resolução de problemas verbais de estrutura aditiva: uma perspectiva construtivista. In: Simões, M.C.T. et al. (Orgs.). Psicologia do desenvolvimento: temas de investigação. Coimbra: Edições Almedina, 2006, p. 53-76.

BROUSSEAU, G. Theory of didactical situations in mathematics. Dordrecht: Kluwer Academic Plublishers, 1997.

CASÁVOLA, H. M. et al. O papel construtivo dos erros na aquisição dos conhecimentos: contribuição para um a teoria das aprendizagens. In: CASTORINA, J.A. e cols. (Orgs.) Psicologia genética: aspectos metodológicos e implicações pedagógicas. Porto Alegre: Artes Médicas, 1988, p. 32-44.

CASTRO, J. et al. Abordagem construtivista do erro na resolução de problemas de aritmética de estrutura aditiva. Da investigação às práticas: estudos de natureza educacional, v. 7, n.1, p.129-149, 2006.

CRUZ, M. S. S.; SPINILLO, A.G. Resolvendo adição de frações através do simbolismo matemático e através de âncoras. Revista Quadrante, v.13, n.2, p. 3- 30, 2004. 
CURY, H. N. Análise dos Erros: o que podemos aprender com as respostas dos alunos. Belo Horizonte: Autêntica, 2008.

CURY, H. N. O conhecimento pedagógico do conteúdo dos erros. In: CURY, H.N.; VIANNA, C.R. (Orgs.), Formação do professor de matemática: reflexões e propostas. Santa Cruz do Sul: Editora IPR, 2012, p.19-48.

FLAVELL, J. Speculations about the nature and development of metacognition. In: WEINERT, F.; KLUWE, R. (Orgs.), Metacognition, motivation and understanding. Hillsdale, NJ.: Lawrence Erlbaum, 1987, p. 21-29.

GITIRANA, V. Planejamento e avaliação em matemática. In: SILVA, J.F. da;. HOFFMANN J.; ESTEBAN, M.T. (Orgs.) Práticas avaliativas e aprendizagens significativas em diferentes áreas do currículo. Porto Alegre: Mediação, 2012, p. 5968.

GITIRANA, V. et al. Repensando multiplicação e divisão: contribuições da teoria dos campos conceituais. São Paulo: PROEM, 2014.

GÓMEZ, A. B. Tipologia de los errores en el cálculo mental: un estudio em el contexto educativo. Enseñanza de las Ciências, v.13, n.3, p.313-325, 1995.

JOU, G. I. de; SPERB, T. M. A metacognição como estratégia reguladora da aprendizagem. Psicologia Reflexão e Crítica, v.19, n.2, p. 177-185, 2006.

LAUTERT, S. L.; SPINILLO, A. G.; CORREA, J. Children's difficulties with division: an intervention study. Educational Research, v. 3, n.5, p. 447-456, 2012.

MACEDO, L. de. Para uma visão construtivista do erro no contexto escolar. In: AGUIAR, C. de T. (Org.). Coletânea de Textos de Psicologia. São Paulo: Secretaria da Educação/ Coordenadoria de Estudos e Normas Pedagógicas, 1990, p.75-84.

MOREN, E. B. S.; DAVID, M. M. M. S; MACHADO, M. P. L. Diagnóstico e análise de erros em matemática: subsídios para o processo ensino-aprendizagem. Cadernos de Pesquisa, n.83, p.43-51, 1992.

PACHECO, A. B.; MEDEIROS, C. F. Uma investigação sobre as dificuldades no uso de estratégias para a resolução de problemas verbais no campo da análise combinatória. In: MARANHÃO, C. (Org.) Educação matemática nos anos finais do ensino fundamental e no ensino médio: pesquisa e perspectivas. São Paulo: Musa Editora, 2009, p. 76-98.

PENG, A.; LUO, Z. A framework for examining mathematics teacher knowledge as used in error analysis. For the learning of Mathematics, v.29, n.3, p. 22-25, 2009.

PINTO, N. B. O erro como estratégia didática: o estudo do erro no ensino da matemática elementar. São Paulo: Papirus, 2000.

RADATZ, H. Error analysis in Mathematics Education, Journal for Research in Mathematics Education, v.10, n.2, p. 163-172, 1979. 
RIBEIRO, C. Metacognição: Um apoio ao processo de aprendizagem. Psicologia Reflexão e Crítica, v.16, n. 1, p. 109-116, 2003.

SANTOS, J. R. V. dos; BURIASCO, R. L. C. Da ideia de erro para as Maneiras de Lidar: Caracterizando nossos alunos pelo que eles têm e não pelo que lhes falta. In: BURIASCO, R. L. C. de (Org.) Avaliação e educação matemática. Recife: SBEM, 2008, p. 87-108.

SPINILLO, A. G. As relações entre aprendizagem e desenvolvimento discutidas a partir de pesquisas de intervenção. Arquivos Brasileiros de Psicologia, v. 51, n.1, p. 55-74, 1999.

SPINILLO, A. G. Avaliação da aprendizagem numa perspectiva cognitiva. Psychologica, n. 14, p.83-99, 1995.

SPINILLO, A. G. Ensinando proporção a crianças: alternativas pedagógicas em sala de aula. Boletim GEPEM Grupo de Estudos e Pesquisas em Educação Matemática, v.43, n. 3, p. 11-47, 2003.

SPINILLO, A. G.; SILVA, J. F. G. Making Explicit the principles governing combinatorial reasoning: Does it help children to solve Cartesian product problems? Proceedings of the $34^{\text {rd }}$ Conference of the International Group for the Psychology of Mathematics Education, p. 216-224, 2010.

TORRE, S. de la. Aprender com os erros: o erro como estratégia de mudança. Porto Alegre: Artmed, 2007. 